\title{
CHIARITÉ
}

UNIVERSITÄTSMEDIZIN BERLIN

\section{Amused, accepted, and used? Attitudes and emotions towards automated vehicles, their relationships, and predictive value for usage intention}

Jan C. Zoellick, Adelheid Kuhlmey, Liane Schenk, Daniel Schindel, Stefan Blüher

\section{Document type}

Postprint (accepted version)

This version is available at

https://refubium.fu-berlin.de/handle/fub188/25358

\section{Citation details}

Zoellick JC, Kuhlmey A, Schenk L, Schindel D, Blüher S. Amused, accepted, and used? Attitudes and emotions towards automated vehicles, their relationships, and predictive value for usage intention. Transportation Research Part F: Traffic Psychology and Behaviour. [Online] Elsevier BV; 2019;65: 68-78. DOI: 10.1016/j.trf.2019.07.009

\section{Terms of use}

This work is licensed under a Creative Commons Attribution-NonCommercial-NoDerivatives 4.0 International license: https://creativecommons.org/licenses/by-nc-nd/4.0/ 
Amused, accepted, and used? Attitudes and emotions towards automated vehicles, their relationships, and predictive value for usage intention.

Jan C. Zoellick ${ }^{a *}$, Adelheid Kuhlmeya, Liane Schenk ${ }^{a}$, Daniel Schindela ${ }^{a}$ Stefan Blüher ${ }^{a}$

a Charité - Universitätsmedizin Berlin, corporate member of Freie Universität Berlin, Humboldt-Universität zu Berlin, and Berlin Institute of Health Institute of Medical Sociology and Rehabilitation Science, Charitéplatz 1, 10117 Berlin, Germany

* Corresponding author.

E-Mail: jan.zoellick@charite.de

\begin{abstract}
Automated vehicles (AVs) have left the laboratories and can be experienced in several projects, e.g. at the premises of a clinic in Germany. With this transition, research on AV attitudes no longer needs to rely on questionnaires with hypothetical scenarios and simulations. Previous research - limited by the unavailability of AVs - has provided ambivalent results regarding age and gender differences in attitudes towards AVs. We present research results about the role of age and gender in connection with attitudes such as acceptance, perceived safety, and trust, as well as intention to use. We additionally demonstrate relationships between those constructs and emotions such as amusement, fear, and surprise. Data were collected from participants $(n=125)$ after having experienced an AV ride with level 4 automation on two campuses of a clinic in Berlin, Germany. Results reveal strong correlations between all attitudes $(.55 \leq r \leq .71 ; p<.01)$ and show acceptance and perceived safety to be solid predictors of intention to use AVs. We also found age to be a significant predictor for usage intention even when other attitudes are considered $(\beta=-0.22 ; p<.01)$. MANOVA results point to gender differences in all constructs, but with limited confidence $(5.40 \leq F \leq 18.34 ; p \leq .02)$. However, we reject our hypothesis that young men are highly accepting, trusting, and intending to use AVs compared to other combinations of age and gender. We recommend using a mix of attitude, emotion, and behavioural (intention) measures in future research on $\mathrm{AVs}$ together with more transparency regarding construct definitions and study materials.
\end{abstract}

Keywords: autonomous driving; physical experience of automated vehicles; technology acceptance; trust in automated vehicles; emotions towards automated vehicles 


\section{Introduction}

Automated vehicles (AVs) are the mobility application of digitalisation. We define AVs as shared vehicles that are, electrically powered, and able to perform "all driving functions under certain conditions" (NHTSA, 2017, p. 4). They look unfamiliar being equipped with multiple sensors monitoring their surroundings and without the need for many features of regular cars, e.g. steering wheel or aligned seats (Nordhoff, van Arem, \& Happee, 2016). Figure 1 depicts an example of such a vehicle used in the present study. It can transport up to 15 people with a maximum speed of $12 \mathrm{~km} / \mathrm{h}$ and is electrically powered. It navigates through GPS signals and LIDAR sensors alongside a programmed route. With these features, the behaviour of AVs differs from humans in their communication with passengers, pedestrians, and other road users. Thus, attitudes of road users might be key to understand the prospects of this emerging technology (Nordhoff et al., 2016; Rahman, Lesch, Horrey, \& Strawderman, 2017; Van der Laan, Heino, \& de Waard, 1997).

The aim of this paper is to understand relationships between attitudes and behavioural intentions towards $\mathrm{AVs}$ and their connection with sociodemographic variables. For this purpose, we present research results from a survey following physical experience as users of an $\mathrm{AV}$ at the premises of a clinic in Berlin, Germany. With increased validity compared to hypothetical scenarios or simulation studies, we test hypotheses regarding (1) the relationship between acceptance, trust, perceived safety, and behavioural intentions, (2) sociodemographics of users, and (3) a model predicting intention to use AVs in the future.

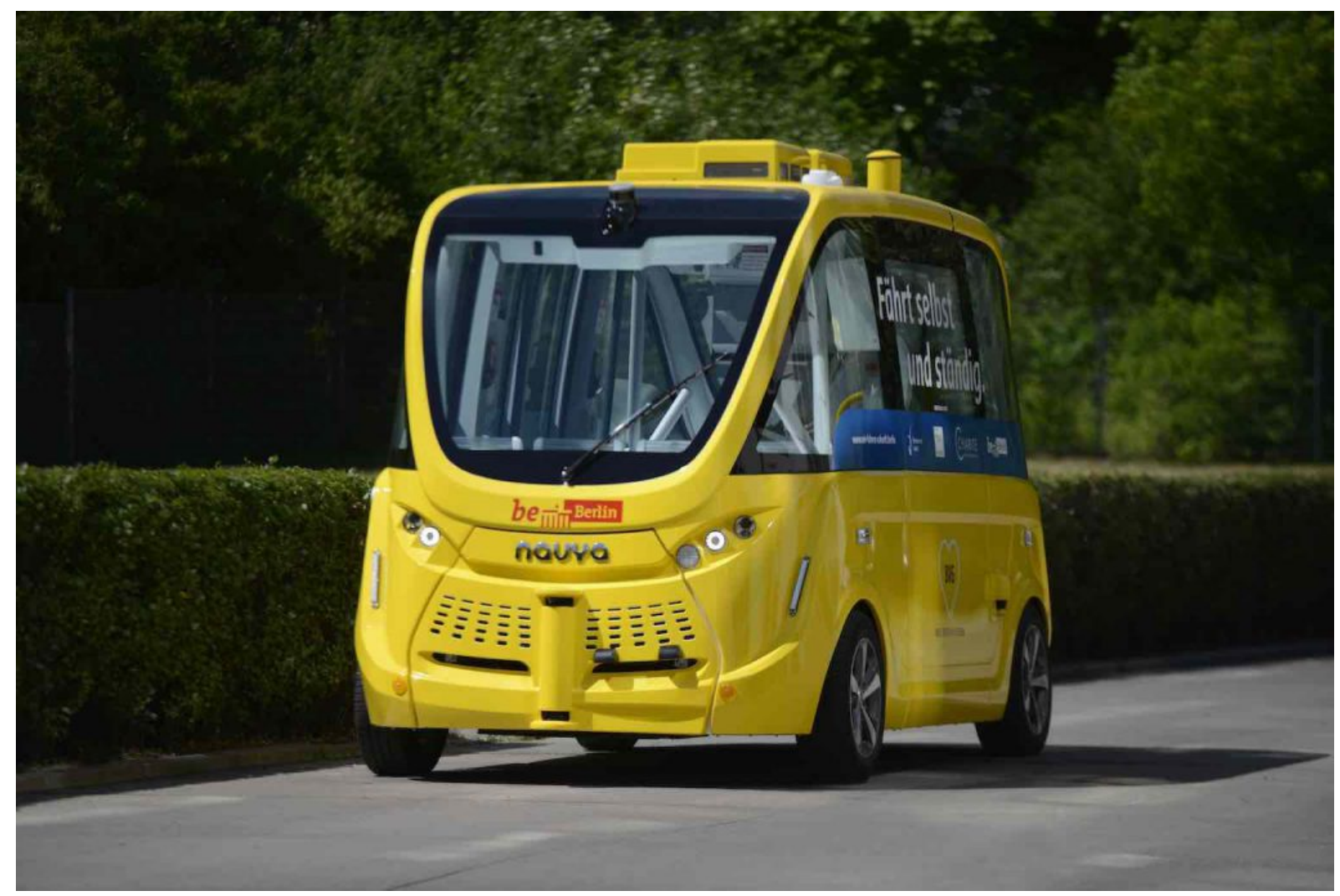


Figure 1. Navya Arma with level-4 automation at the Charité Virchow Klinikum. By Charité - Universitätsmedizin Berlin, 2018, retrieved from https://www.wir-fahrenzukunft.de/bilder/\#iLightbox[gallery image 1]/34 Licensed under a CC BY 2.0 license

The remainder of the article is organised as follows. First, we review the literature regarding AV attitudes and behavioural intentions, their results regarding age and gender, and corresponding hypotheses. Second, we define all relevant constructs, describe the procedure in this study, and depict the analysis plan. Third, we provide results of all scales, our power calculation, and the hypothesis testing. Lastly, we discuss all findings amidst relevant limitations and draw conclusions from this study.

\section{Literature, Model, and Hypotheses}

Models about AV attitudes typically include variables such as social acceptability, willingness to pay, usefulness, or intentions to use as outcomes predicted by pleasure, arousal, socio-demographics, perceived safety, or trust (Nordhoff et al., 2016; Osswald, Wurhofer, Trösterer, Beck, \& Tscheligi, 2012). However, as AVs had been unavailable until recently, most studies relied on simulations (Cho, Park, Park, \& Jung, 2017; Verberne, Ham, \& Midden, 2015) or hypothetical scenarios (Bansal \& Kockelman, 2017; Krueger, Rashidi, \& Rose, 2016; Nordhoff, de Winter, Kyriakidis, van Arem, \& Happee, 2018). This came at the cost of validity. Limitations of many studies include uncertainty about the transferability and applicability of their findings to physical use cases (Bansal \& Kockelman, 2017; Fraedrich \& Lenz, 2016; Krueger et al., 2016). Method diversity within AV attitude research (Adell, Várhelyi, \& Nilsson, 2014) adds to validity concerns and seems to create more uncertainty and confusion as apparent in the ambivalence of results regarding age and gender in connection with $\mathrm{AV}$ attitudes and behavioural intentions.

Some studies find older people to be more trusting, accepting, and conscious about benefits of AVs leading them to higher willingness to pay (Regan et al., 2017; Rödel, Stadler, Meschtscherjakov, \& Tscheligi, 2014). Others, in contrast, found higher willingness to pay for younger people (Bansal \& Kockelman, 2016; Bansal, Kockelman, \& Singh, 2016). Similarly, researchers found a positive correlation of age with intention to use AVs (Nordhoff, de Winter, Madigan, et al., 2018) and a negative one with willingness to use AVs (Hohenberger, Spörrle, \& Welpe, 2017). Older people also decided against both privately owned and shared AVs in favour of regular cars in a stated preference design (Haboucha, Ishaq, \& Shiftan, 2017). Payre, Cestac, and Delhomme (2014) did not find age effects on intention to use in three hierarchical regression analyses at all. However, being female was a predictor in their base model. This gender effect was devoured once they introduced acceptability and attitudes to the equation. In contrast, being male predicted willingness to use in Hohenberger et al.'s (2017) regression. Men were more willing to use, derive pleasure from, and less anxious about AVs than women (Hohenberger, Spörrle, \& Welpe, 2016). Madigan, Louw, Wilbrink, Schieben, and Merat (2017) 
and Nordhoff, de Winter, Madigan, et al. (2018) - to our knowledge the only study with participants actually experiencing an AV - did not find gender effects for intention to use. Kyriakidis, Happee, and de Winter (2015) found neither clear age nor gender effects on willingness to pay, comfort, or enjoyment.

In contrast to unclear gender and age effects, relationships between constructs are more evident. Choi and Ji (2015) found trust to be a significant predictor of behavioural intention to use, perceived usefulness of, and perceived risk of AVs in a multiple. Nordhoff, de Winter, Madigan, et al. (2018) found a positive correlation between two principal components reflecting intention to use and the perceived effectiveness of the AV. Rödel et al. (2014) found a correlation between intention to use and attitudes, i.e. evaluations on a favourable/unfavourable dimension. Similarly, Hohenberger et al. (2016) found willingness to use AVs positively correlated with pleasure and negatively with anxiety. Unfortunately, many of the studies reporting age and gender differences either only included one attitude in their otherwise socio-demographic survey (Bansal \& Kockelman, 2016, 2017; Bansal et al., 2016) or did not model and test relationships between the attitudes (Kyriakidis et al., 2015; Regan et al., 2017).

This very short overview does not even take into account methodological differences, reliability measures, or validity issues resulting from different study designs. These concerns lead to a chastening conclusion - knowledge about peoples' assessment of AVs might not be as dependable as depicted. It seems the only certainty in acceptance research is the widely held assumption that "acceptance is the precondition that will permit new [...] technologies to achieve their forecasted benefit levels" (Najm, Stearns, Howarth, Koopmann, \& Hitz, 2006, p. 5-1).

In our pre-registration, we have formulated the research question "What do participants think of fully automated vehicles and what is their degree of acceptance?" We can specify and translate this into testable hypotheses. Based on previous studies (e.g., Nordhoff et al., 2016; Osswald et al., 2012) we expect to find the following:

Hypothesis 1: The constructs acceptance, trust, perceived safety, and intention to use correlate.

Hypothesis 2: Young men score significantly higher on the scales acceptance, trust, and intention to use than young women, old men, and old women.

Hypothesis 3: Socio-demographic variables (age and gender) lose predictive power for intention to use when adding latent constructs (acceptance, trust, and perceived safety) 
Figure 2 portrays the relationship between the variables acceptance, perceived safety, trust, and intention to use with age and gender as socio-demographic variables as described in hypothesis 3 . The model depicts a hierarchical regression analysis in which being male and younger predict higher intention to use as a baseline model. We successively add acceptance, trust, and perceived safety as predictors. We expect the explained variance to increase significantly with every step and coefficients for the socio-demographics to become smaller and less or non-significant.

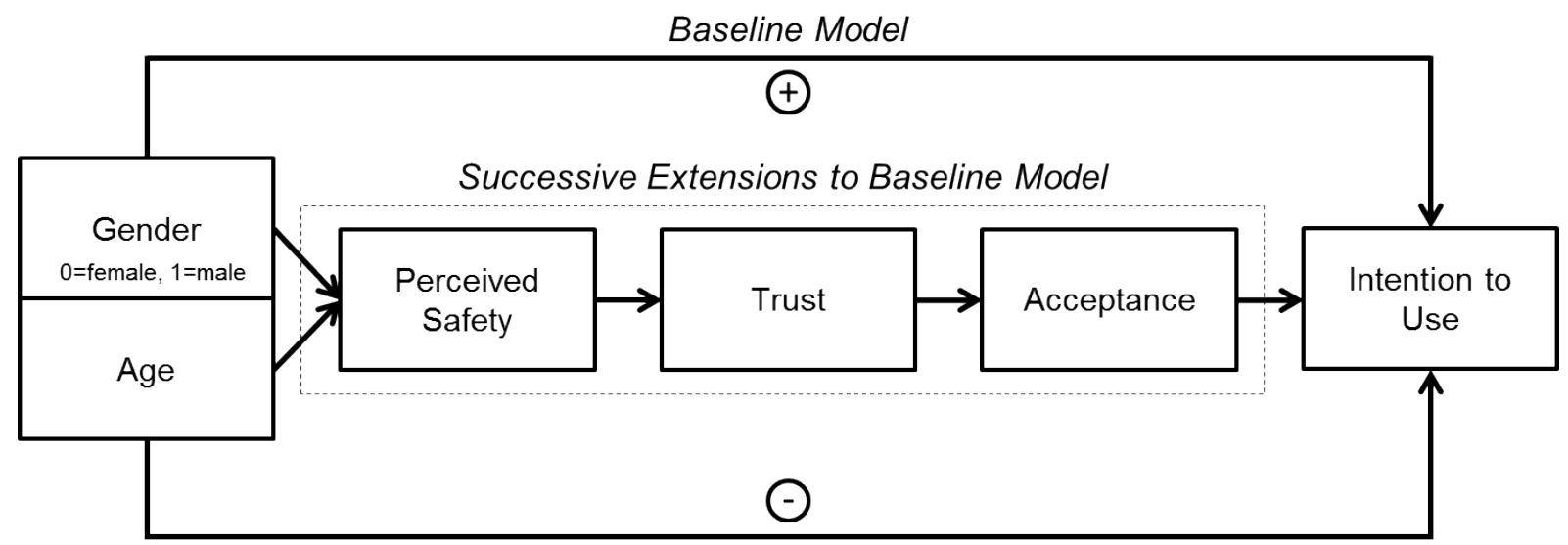

Figure 2. Conceptual model of the relationships between socio-demographics, attitudes, and behavioural outcomes. Hierarchical regression analyses with age and gender predicting intention to use as a baseline model and successive addition of acceptance, trust, and perceived safety.

\section{Materials and Methods}

\subsection{Definitions and Measures}

Previous literature has identified a range of variables of interest when considering user experience in AVs. Among them are acceptance, intention to use, perceived safety, and trust as well as emotions varying in their degree of valence and activation. However, construct definitions and the full list and origin of items are absent in many articles on these constructs (e.g., Adell et al., 2014; Nordhoff, de Winter, Madigan, et al., 2018; Schaefer, Chen, Szalma, \& Hancock, 2016; Schieben, Griesche, Hesse, Fricke, \& Baumann, 2014; Spyropoulou, Karlaftis, \& Reed, 2014). To counteract this trend, we provide detailed accounts of all constructs and measures, and refer to our pre-registration for additional information (registration link https://osf.io/92pv5/). Our questionnaire contained 36 items and can be found in the supplementary materials in its original German and a translated English version. We asked for age, gender, driver's license, and provided an open item for comments.

3.1.1 Acceptance. In line with Van der Laan et al. (1997, p. 2), we define acceptance as "direct attitudes towards a system, i.e. predispositions to respond, or tendencies in terms of 
'approach/avoidance' or 'favourable/unfavourable'”. This definition stands in contrast to behavioural conceptions, e.g. from Adell (2009). Her acceptance definition corresponds to our conception of intention to use, not acceptance. Accordingly, we used the five-point semantic differential with attitudes developed by Van der Laan et al. (1997) as operationalisation of acceptance.

3.1.2 Intention to use. We define intention to use as "a person's location on a subjective probability dimension involving a relation between himself and some action" - in our case taking a ride in an automated vehicle (Fishbein \& Ajzen, 1975, p. 288). For measurement, we used three items developed by Osswald et al. (2012) on a five-point Likert scale ranging from disagree (1) to agree (5).

3.1.3 Perceived safety. In accordance with Osswald et al. (2012, p. 55), perceived safety is defined as "the degree to which an individual believes that using [AVs] will affect his or her well-being", both generally and with consideration of attention/distraction. We used items 1, 2, 4 , and 5 from their six-item scale on a five-point Likert scale ranging from disagree (1) to agree (5). We excluded items 3 and 6 beforehand, because they could not be adapted to AVs in a sensible way. We added a self-constructed item about general perceptions of safety when thinking of AVs.

3.1.4 Trust. We adapted Pavlou's (2003, p. 106) definition of trust as "the belief that allows [users] to willingly become vulnerable to [automated vehicles] after having taken [its] characteristics into consideration". Our operationalisation includes three adapted items from Pavlou (2003) to fit the context of AVs (cf. Choi \& Ji, 2015).

3.1.5 Emotions. We understand any emotion as a "complex phenomenon having neurophysiological, motor-expressive, and experiential components" (Izard, 1977, p. 64). However, the experiential component is the only one we measured. The four emotions definitions as conscious experiences can be found in Table 1. For measurement of surprise and fear, we used the DAS (Merten \& Krause, 1993), and for boredom and amusement, we used the modified M-DAS (Renaud \& Unz, 2006). All emotions were ranked on a five-point Likert scale ranging between very weak (1) and very strong (5).

Table 1

Definitions of the Emotions Amusement, Fear, Surprise, and Boredom

\begin{tabular}{cl}
\hline Concept & \multicolumn{1}{c}{ Definition } \\
\hline Amusement & $\begin{array}{l}\text { High arousal and positive valence belonging to the emotional family of joy } \\
\text { (Izard, 1977; Scherer, 2005) }\end{array}$
\end{tabular}


High arousal and negative valence more activating than but related to

Fear distress with the potential to trigger 'fight or flight' behavioural responses (Izard, 1977)

Surprise

High arousal sparked by misexpected stimuli (positive or negative) resulting in a short-term behavioural impetus (Izard, 1977)

Boredom Low arousal and slightly negative valence resulting from languidness and indifference (Izard, 1977; Scherer, 2005)

\subsection{Procedure}

We collected data at the Long Night of the Sciences - a special event of museums, universities, and other knowledge institutions in Berlin and Potsdam on 9 June 2018. On the two Charité campuses Virchow-Klinikum (CVK) and Mitte (CCM), visitors were invited to ride an $\mathrm{AV}$ along round courses with $0.85 \mathrm{~km}$ and $1.20 \mathrm{~km}$ length, respectively, lasting 10 to 15 minutes. Both courses represented realistic traffic environments with intersections necessitating turns, cycle paths, and crosswalks and with corresponding road users. The model EZ10 from Easymile drove at CCM; the model Arma from Nayva drove at CVK. Both AVs drove a maximum of $12 \mathrm{~km} / \mathrm{h}$, navigated through GPS signals and LIDAR sensors, and were electrically powered. They were able to perform all driving functions automatically alongside the programmed routes. The routes are presented in Figure 3 with highlighted routes. A so-called operator for manual control supported each $A V$ if the vehicle was overextended. The Berliner Verkehrsbetriebe (BVG) and the Berlin Senate Department for the Environment, Transport and Climate Protection were involved as project partners.

(A)

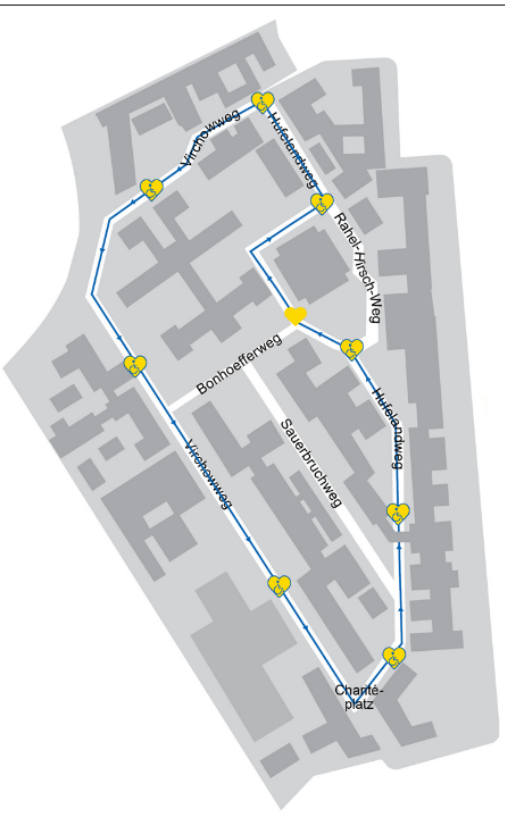

(B)

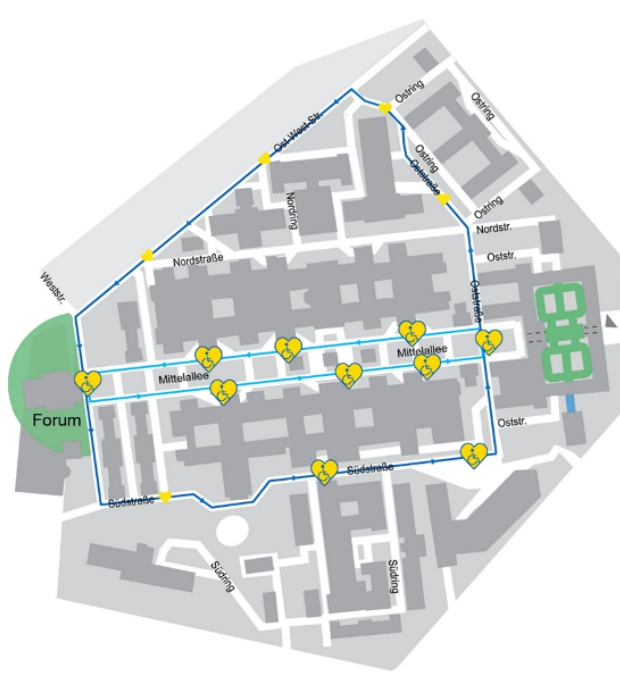


Figure 3. Maps of the campus areas with AV routes marked in blue. Hop-on-hop-off stations depicted as yellow hearts; wheelchairs symbolise stations equipped for the disabled. (A) Charité Campus Mitte with AVs driving counter clockwise. (B) Charité Virchow Klinikum with AVs driving counter clockwise; route of the AVs used in the pilot study in light blue; route additionally used in the project in dark blue. Originally by Charité - Universitätsmedizin Berlin, 2018, retrieved from https://www.wir-fahren-zukunft.de/en/the-routes/ Licensed under a CC BY 2.0 license; figure and caption adopted from Zoellick, Kuhlmey, Schenk, Schindel, and Blüher (2019).

We addressed passengers exiting the $\mathrm{AVs}$ at two highly frequented stations on each campus with an invitation to participate in our study. After explicating voluntariness, data processing for scientific purposes, anonymity, etc., and providing a sheet with these information in writing, we handed them the two-page questionnaire. Participants took between 5 and 10 minutes to complete the 36 items and did not receive material compensation. In accordance with our registration, we did not exclude people from participating, i.e. people under the age of 18 or without driver's license were included in the analyses.

\subsection{Sample}

The 125 participants ( $50 \%$ male) were on average 33.00 years old ( $S D=16.35$ years). $31 \%$ of participants did not have a driver's license. $56 \%$ of those were under 17 years old, i.e. the age to legally obtain a driver's license in Germany. 39\% participated at CVK and 61\% at CCM.

\subsection{Analysis}

As preliminary analyses, we calculated Little's MCAR test and imputed randomly missing data using expectation maximisation in SPSS 25 (IBM Corp., 2017). We then calculated exploratory factor analyses (EFAs) with oblimin rotation as well as reliability analyses on all scales.

Based on these preliminary results, we excluded one item from the perceived safety scale and the emotion boredom from further analyses. We used the acceptance mean, intention to use, trust, and perceived safety factor scores resulting from EFAs, and sum scores for the emotions amusement, fear, and surprise for further analyses. For further insights, we calculated means and other descriptive statistics on the scales intention to use, trust, and perceived safety. For all scales, we tested if they were significantly different from their neutral middle by calculating two-tailed t-tests with one sample setting Bonferroni adjusted alpha levels at $.05 / 8=.006$ and $.01 / 8=.001$.

We used G*Power 3.1 (Faul, Erdfelder, Buchner, \& Lang, 2009) to calculate the achieved power of our test. For regressions (fixed model, $R^{2}$ deviation from zero), we set the effect size $\mathrm{f}^{2}$ of .1 , alpha-level of .05 , sample size of 125 , and 5 predictors. For correlations (bivariate normal model, two-tailed), we set $\rho \mathrm{H} 1$ of 0.2 , alpha-level of .05 , sample size of 125 , and $\rho \mathrm{H} 0$ 
of 0 . We also calculated the effect sizes we were able to identify with a power of .80 ceteris paribus. This calculation estimates the robustness of our analyses given a fixed sample size. Thus, we can contextualise and interpret results even from small samples.

We calculated two-tailed parametric (Pearson's $r$ ) and non-parametric (Spearman's $\rho$ ) correlations between acceptance, perceived safety, intention to use, trust, and those emotion scales providing adequate reliability and factor loadings. With (ordinal) Likert items and nonnormally distributed data in the case of fear, we violated often-cited assumptions necessary for using parametric statistics (Norman, 2010). We calculated both for comparative purposes.

For testing our second hypothesis, we split the data set along the median in younger $(\leq 33$ years) and older ( $\geq 34$ years) participants. We then calculated a one-way MANOVA with age and gender as factors, and acceptance, perceived safety, trust, and intention to use as outcomes.

Approaching the third hypothesis, we calculated the model displayed in Figure 2 as hierarchical regression analyses after testing several assumptions - namely linearity, normal distribution of the outcome, sample size compared to number of predictors, multicollinearity, outliers, and homoscedasticity. Starting with continuous age and dichotomous gender as predictors and intention to use as outcome, we successively added acceptance, trust, and perceived safety as predictors. This resulted in four models for comparison. Violating the assumption of linearity, we introduced quadratic terms for our continuous predictors and compared this fifth model with the results of the previous four.

\section{Results}

\subsection{Preliminary Analyses}

With $3 \%$ missing data, Little's MCAR test retrieved significant results $\left(x^{2}=573.164\right.$, $\mathrm{df}=496, \mathrm{p}=.009$ ). However, upon exploring the data structure, we could not identify systematic missing values. Therefore, we assumed random missing values and imputed data. In factor analyses acceptance, fear, and surprise formed unique factors (Zoellick et al., 2019). All items of the scales trust, intention to use, and amusement loaded on one respective factor, however with cross-loadings from perceived safety and boredom items. Thus, the scales perceived safety and boredom did not form their predicted factors. After excluding the crossloading item, perceived safety items formed a coherent factor. Descriptive statistics, deviation from the scale's neutral middle, and reliability coefficients for all scales are displayed in Table 2.

Table 2 
Descriptive Statistics, Two-tailed t-test Results, and Reliability Coefficients of Attitudes, Behavioural Intention, and Four Emotions.

\begin{tabular}{|c|c|c|c|c|c|c|c|}
\hline Variable & $\begin{array}{l}\text { Scale } \\
\text { range }\end{array}$ & Median & $\begin{array}{l}\text { Mean } \\
\text { (SD) }\end{array}$ & Skew & KU & $t$ & $\alpha$ \\
\hline Acceptance & +2 to -2 & 1.22 & $\begin{array}{c}1.18 \\
(0.70)\end{array}$ & -0.96 & 0.80 & $18.73^{* *}$ & .91 \\
\hline Perceived safety & 1 to 5 & 3.33 & $\begin{array}{c}3.29 \\
(1.03)\end{array}$ & -0.16 & -0.54 & $3.12^{*}$ & .69 \\
\hline Intention to use & 1 to 5 & 4.00 & $\begin{array}{c}3.68 \\
(1.05)\end{array}$ & -0.47 & -0.77 & $7.22^{\star *}$ & .83 \\
\hline Trust & 1 to 5 & 3.27 & $\begin{array}{c}3.29 \\
(0.81)\end{array}$ & -0.08 & 0.51 & $3.97^{\star \star}$ & .77 \\
\hline Amusement & 3 to 15 & 12.00 & $\begin{array}{l}11.66 \\
(2.24)\end{array}$ & -0.43 & -0.06 & $13.31^{* *}$ & .77 \\
\hline Fear & 3 to 15 & 3.00 & $\begin{array}{c}3.87 \\
(1.72)\end{array}$ & 2.39 & 6.86 & $-33.40^{* *}$ & .81 \\
\hline Surprise & 3 to 15 & 10.00 & $\begin{array}{c}9.86 \\
(3.08)\end{array}$ & -0.16 & -0.54 & $3.12^{*}$ & .86 \\
\hline Boredom ${ }^{\dagger}$ & 3 to 15 & 5.00 & $\begin{array}{c}5.62 \\
(2.49)\end{array}$ & 0.76 & 0.17 & $-15.18^{* *}$ & .63 \\
\hline
\end{tabular}

Note. $\mathrm{SD}=$ standard deviation; $\mathrm{KU}=$ excess kurtosis; $\alpha=$ Cronbach's alpha. † We dropped boredom from further analyses. ${ }^{*} p<.006 .{ }^{* *} p<.001$. Table based on Tables 9 and 10 in Zoellick et al. (2019).

\subsection{Power analysis}

We identified actual test power of .77 for regression analyses and .61 for correlations. Effect sizes we could identify with a power of .80 were $\mathrm{f}^{2}=.11$ for regressions and $\rho \mathrm{H} 1$ of .25 for correlations. Even with an arguably small sample size of $n=125$ we are able to produce robust results with high certainty for correlations $|r| \geq .25$ and regressions $f^{2} \geq .11$.

\subsection{Hypothesis Testing}

Correlation results support our first hypothesis, because all correlations between attitudes and behavioural intentions were significant and $|\gamma| \geq .25$ respective $|\rho| \geq .25$, i.e. the size we could detect with a power of 80 or higher. However, correlations with the emotions were either unintuitive or undependable. Fear correlated neither with acceptance nor with trust, and unconfidently with perceived safety. Despite significance, all correlations between amusement and attitudes $(|r|<.25$ respective $|\rho|<.25)$ fell in the range of small certainty. Surprise did not correlate with any of the attitude measures. All correlations are displayed in Tables 3 and 4 . 
Table 3

Two-tailed Parametric Correlations (Pearson's r) between Seven Latent Constructs and Age

\begin{tabular}{lcccccccc}
\hline Measure & ACC & SAFE & I-USE & TRU & AMU & SUR & FEAR & AGE \\
\hline ACC & - & & & & & & & \\
SAFE & $.61^{* *}$ & - & & & & & & \\
I-USE & $.60^{* *}$ & $.58^{* *}$ & - & & & & & \\
TRU & $.56^{* *}$ & $.71^{* *}$ & $.55^{* *}$ & - & & & & \\
AMU & $.18^{*}$ & .09 & .14 & .17 & - & & & \\
SUR & .11 & -.09 & -.07 & -.03 & $.25^{* *}$ & - & & \\
FEAR & -.15 & $-.21^{*}$ & $-.26^{* *}$ & -.07 & -.07 & $.25^{* *}$ & - & \\
AGE & -.08 & .01 & $-.26^{* *}$ & $-.21^{*}$ & $-.28^{* *}$ & $-.25^{* *}$ & -.12 & - \\
\hline
\end{tabular}

Note. $n=125$. ACC = acceptance; SAFE = perceived safety; I-USE = intention to use;

TRU = trust; $A M U$ = amusement; SUR = surprise; $F E A R=$ fear; $A G E$ = age. ${ }^{*} p<.05 .{ }^{* *} p<.01$

Table 4

Two-tailed Non-parametric Correlations (Spearman's $\rho$ ) between Seven Latent Constructs and Age

\begin{tabular}{lcccccccc}
\hline Measure & ACC & SAFE & I-USE & TRU & AMU & SUR & FEAR & AGE \\
\hline ACC & - & & & & & & & \\
SAFE & $.58^{* *}$ & - & & & & & & \\
I-USE & $.57^{* *}$ & $.58^{* *}$ & - & & & & & \\
TRU & $.58^{* *}$ & $.67^{* *}$ & $.51^{* *}$ & - & & & & \\
AMU & $.24^{*}$ & .09 & $.21^{*}$ & $.22^{*}$ & - & & & \\
SUR & .11 & -.08 & -.06 & -.01 & $.25^{* *}$ & - & & \\
FEAR & -.15 & $-.20^{*}$ & $-.27^{* *}$ & -.11 & -.09 & $.21^{*}$ & - & \\
AGE & -.04 & .00 & $-.26^{* *}$ & $-.21^{*}$ & $-.29^{* *}$ & $-.28^{* *}$ & -.10 & -
\end{tabular}

Note. $n=125$. ACC = acceptance; SAFE = perceived safety; I-USE = intention to use; $\mathrm{TRU}=$ trust; $\mathrm{AMU}=$ amusement; SUR = surprise; $\mathrm{FEAR}=$ fear; $A G E$ = age. ${ }^{*} p<.05 .{ }^{* *} p<.01$

Parametric and non-parametric correlations provided slightly different results. Most obviously, the correlations of amusement with intention to use and with trust were significant at .05-level in Spearman, but not in Pearson. The correlation between surprise and fear was significant at .01-level in Pearson, but at .05-level in Spearman. Both methods provided the same coefficient in 4 out of 15 shared significant correlations with Pearson overestimating four and Spearman overestimating seven correlation coefficients. This stands in contrast to Norman who argues that small sample sizes, non-normally distributed data, and ordinal Likert items do not skew results from parametric statistics, as they "are robust with respect to violations of these assumptions" (Norman, 2010, p. 625). Our data indicates that both 
procedures overlap largely regarding significance estimates, but differ in their coefficient estimates.

Group sizes of our MANOVA as a test of our second hypothesis varied between old women $(n=22)$, old men ( $n=25)$, young men $(n=37)$, and young women $(n=41)$. We found significant results for Box's test $(F(30,25693)=2.38, p<.001)$, Levene's tests for acceptance $(F(3,121)=7.12, p<.001)$ and intention to use $(F(3,121)=6.01, p=.001)$, and Pillai's traces for age $(F(4,118)=3.57, p=.004)$ and gender $(F(4,118)=2.88, p=.001)$. Thus, we rejected the assumption of homogeneous variance-covariance matrices (Huberty \& Petoskey, 2000). Consequently, we set stricter alpha levels at $p=.001$ (Allen \& Bennett, 2007) when evaluating MANOVA results for acceptance, perceived safety, intention to use, and trust presented in Tables 5 to 8 , respectively. None of the investigated groups - particularly the hypothesised young men compared to other combinations of age and gender - differed significantly regarding acceptance, perceived safety, intention to use, and trust in AVs. Thus, we reject our second hypothesis.

Table 5

MANOVA Results for Acceptance

\begin{tabular}{llllll}
\hline Predictor & $\begin{array}{l}\text { Sum of } \\
\text { Squares }\end{array}$ & $\mathrm{df}$ & $\mathrm{F}$ & $\mathrm{p}$ & $\eta$ \\
\hline Constant & 159.21 & 1 & $337.98^{*}$ & .000 & .736 \\
Gender & 2.69 & 1 & 5.72 & .018 & .045 \\
Age & 0.60 & 1 & 1.28 & .261 & .010 \\
Gender*Age & 0.52 & 1 & 1.11 & .293 & .041 \\
Error & 57.00 & 121 & & & \\
\hline
\end{tabular}

Note. Given non-homogeneous variance-covariance matrices, we set alpha levels at $<.001$ for interpreting significant results. ${ }^{*} p<.001$.

Table 6

MANOVA Results for Perceived Safety

\begin{tabular}{llllll}
\hline Predictor & $\begin{array}{l}\text { Sum of } \\
\text { Squares }\end{array}$ & $\mathrm{df}$ & $\mathrm{F}$ & $\mathrm{p}$ & $\eta$ \\
\hline Constant & 0.00 & 1 & 0.00 & .981 & .000 \\
Gender & 15.95 & 1 & $18.34^{*}$ & .000 & .13 \\
Age & 0.13 & 1 & 0.15 & .699 & .001 \\
Gender*Age & 0.40 & 1 & 0.45 & .499 & .004 \\
Error & 105.22 & 121 & & & \\
\hline
\end{tabular}

Note. Given non-homogeneous variance-covariance matrices, we set alpha levels at $<.001$ for interpreting significant results. ${ }^{*} p<.001$. 
Table 7

MANOVA Results for Intention to Use

\begin{tabular}{llllll}
\hline Predictor & $\begin{array}{l}\text { Sum of } \\
\text { Squares }\end{array}$ & $\mathrm{df}$ & $\mathrm{F}$ & $\mathrm{p}$ & $\eta$ \\
\hline Constant & 0.35 & 1 & 0.40 & .531 & .003 \\
Gender & 5.89 & 1 & 6.72 & .011 & .053 \\
Age & 7.83 & 1 & 8.93 & .003 & .069 \\
Gender*Age & 2.33 & 1 & 2.66 & .106 & .022 \\
Error & 106.12 & 121 & & &
\end{tabular}

Note. Given non-homogeneous variance-covariance matrices, we set alpha levels at $<.001$ for interpreting significant results. ${ }^{*} p<.001$.

Table 8

MANOVA Results for Trust

\begin{tabular}{llllll}
\hline Predictor & $\begin{array}{l}\text { Sum of } \\
\text { Squares }\end{array}$ & df & $\mathrm{F}$ & $\mathrm{p}$ & $\eta$ \\
\hline Constant & 0.20 & 1 & 0.22 & .643 & .002 \\
Gender & 4.95 & 1 & 5.40 & .022 & .043 \\
Age & 4.70 & 1 & 5.12 & .025 & .041 \\
Gender*Age & 1.80 & 1 & 1.96 & .164 & .016 \\
Error & 111.02 & 121 & & &
\end{tabular}

Note. Given non-homogeneous variance-covariance matrices, we set alpha levels at $<.001$ for interpreting significant results. ${ }^{*} p<.001$.

Results from our multiple hierarchical regressions as tests for our third hypothesis showed a violation of linearity. The standard deviation of residuals $(0.72)$ exceeded that of the predicted values (0.70) (Garson, 2012, pp. 44-45). Comparing correlation coefficients (Pearson's $r$ ) with the correlation ratios (eta), we also found $\eta>r$ for all continuous predictors. Thus, linear regressions might not be the best approximation. Consequently, we introduced quadratic terms for acceptance, perceived safety, trust, and age into a fifth model. All other tested assumptions of regressions applied. Our outcome was normally distributed and we obtained more than 20 participants per predictor. For multicollinearity, no pair of predictors correlated higher than .80 , and in collinearity statistics, the minimum tolerance was .37 and the maximum VIF was 2.68 (Garson, 2012). For outliers, Cook's maximum distance was .32, and the range of standardised residuals was between -2.69 and 1.86. For homoscedasticity, we plotted standardized estimates against standardized residuals. All data points laid between -3 and 3 on both axes 
with slightly lower variance at high predicted values compared to low predicted values. However, this pattern did not deviate drastically from random distribution. The results of the multiple hierarchical regression are presented in Table 9.

Table 9

Hierarchical Regression Analyses with Intention to Use as Outcome and Age, Gender, Acceptance, Trust, and Perceived Safety as Predictors.

\begin{tabular}{|c|c|c|c|c|c|c|c|}
\hline & B & SE & $\beta$ & $p$ & $\Delta F$ & $R^{2}$ & $\Delta R^{2}$ \\
\hline Model 1 & - & - & - & - & $9.46^{* \star *}$ & .13 & .13 \\
\hline Constant & 0.29 & 0.20 & - & .154 & & & \\
\hline Age & -0.02 & 0.01 & -0.27 & $.002^{* *}$ & & & \\
\hline Gender & 0.51 & 0.17 & 0.26 & $.003^{* *}$ & & & \\
\hline Model 2 & - & - & - & - & $57.61^{* * *}$ & .41 & .28 \\
\hline Constant & -0.60 & 0.21 & - & $.004^{* *}$ & & & \\
\hline Age & -0.01 & 0.00 & -0.22 & $.002^{* *}$ & & & \\
\hline Gender & 0.25 & 0.14 & 0.13 & .078 & & & \\
\hline Acceptance & 0.78 & 0.10 & 0.55 & $.000^{* * *}$ & & & \\
\hline Model 3 & - & - & - & - & $9.17^{* *}$ & .46 & .04 \\
\hline Constant & -0.44 & 0.21 & - & $.036^{*}$ & & & \\
\hline Age & -0.01 & 0.00 & -0.18 & $.013^{*}$ & & & \\
\hline Gender & 0.20 & 0.14 & 0.10 & .160 & & & \\
\hline Acceptance & 0.59 & 0.12 & 0.41 & $.000^{\star * *}$ & & & \\
\hline Trust & 0.25 & 0.08 & 0.25 & $.003^{* *}$ & & & \\
\hline Model 4 & - & - & - & - & $7.21^{* *}$ & .49 & .03 \\
\hline Constant & -0.16 & 0.23 & - & .466 & & & \\
\hline Age & -0.01 & 0.00 & -0.22 & $.002^{* *}$ & & & \\
\hline Gender & 0.09 & 0.14 & 0.04 & .537 & & & \\
\hline Acceptance & 0.47 & 0.12 & 0.33 & $.000^{* * *}$ & & & \\
\hline Trust & 0.10 & 0.10 & 0.10 & .330 & & & \\
\hline $\begin{array}{l}\text { Perceived } \\
\text { Safety }\end{array}$ & 0.29 & 0.11 & 0.29 & $.008^{\star *}$ & & & \\
\hline
\end{tabular}

Note. $n=125$; gender is coded $0=$ female, $1=$ male; ${ }^{*} p<.05 .,{ }^{* *} p<.01 .,{ }^{* * *} p<.001$

The fifth model with quadratic terms for age, acceptance, trust, and perceived safety explained less variance $\left(R^{2}=.39\right)$ than the fourth model $\left(R^{2}=.49\right)$. Thus, we assumed a linear regression to be a more fitting approximation of the data set. However, the results only partly supported our third hypothesis. Unexpectedly, age remained a significant predictor even when adding all three latent constructs. Gender, however, lost predictive power once we introduced 
acceptance into the regression equation. Perceived safety cannibalised the predictive effect of trust whilst explaining additional variance. Based on our data, the most promising regression equation formed as follows:

$$
Y=-.01 X_{1}+.47 X_{2}+.29 X_{3}
$$

with $Y$ being intention to use, $X_{1}$ being years of age, $X_{2}$ being acceptance and $X_{3}$ being perceived safety.

\section{Discussion}

We analysed relationships between socio-demographics, attitudes, behavioural intentions, and emotions towards AVs using realistic traffic settings and in-vivo experience with this emerging technology. Thus, we expect our results to have high external validity - ideal conditions to test ambivalent findings regarding age and gender from previous studies. Our four main findings were (1) close relationships between the constructs acceptance, perceived safety, trust, and intention to use with different results from parametric and non-parametric analyses, (2) age significantly predicting intention to use but being uncorrelated with the other constructs, (3) a tendency for gender differences in all constructs gender slightly outside significance, and (4) acceptance being the strongest predictor for intention to use AVs followed by perceived safety and age - positioning usefulness of, satisfaction with, and feeling safe in at the centre of AV usage. This is particularly important for actors promoting AVs and researchers evaluating them. In the following, we discuss these findings.

Based on our correlation analyses, we can say with high certainty that the concepts acceptance, perceived safety, trust, and intention to use defined and measured as described in the methods section are closely related. This supports our first hypothesis and replicates previous findings (Choi \& Ji, 2015; Hohenberger et al., 2016; Rödel et al., 2014). For the first time, we introduced emotions measures to research on AVs. Their results, in contrast, are difficult to interpret. The emerging picture suggests that the positive emotion amusement correlates positively and the negative emotion fear negatively with the measured attitudes and behavioural intentions whereas high, neutral activation (surprise) has no relationship with them at all. This would align with naïve modelling of these constructs. However, we found only small and few significant correlations between the emotions and other constructs with very little certainty particularly given our test power. Thus, a first recommendation is increasing the sample size to boost test power. Apart from this aspect, particularly fear might be inappropriate for the research context characterised by an accompanied, slow ride on private property. Anxiety as a more subtle member of this family of emotions might be a better fit. Lastly, these results could be ascribed to the method employed to measure emotions. All scales consisted of three items representing slightly different facets of the respective emotion. A better way 
might be to ask for the overarching emotion directly, e.g. by utilising the Geneva Emotions Wheel (Scherer, 2005; Scherer, Shuman, Fontaine, \& Soriano, 2013). Thus, we first encourage further research combining measures of attitudes, behavioural intentions, and emotions. Different methodologies should provide a clearer picture of their connections. Differences between parametric and non-parametric correlations demonstrate the importance of testing their assumptions and applying the appropriate tool for analysis. We thus argue for rigorous assumption testing and result reporting in further research.

For gender and age, results have to be dissected carefully. Indeed, p-values from our MANOVAs regarding age and particularly gender differences in attitudes and behavioural intentions give some indications, but because of strict alpha levels, only one was significant. We could not identify young men to rank higher on any attitude or behavioural intention than old men, young women, and old women. Thus, we reject our second hypothesis and concede that our MANOVAs did not provide much clarity on age and gender effects. However, insignificant findings for age might be a method effect of our median split combined with a remarkably young sample, assigning people as young as 34 years old to the "older" group. Analysing quartiles or applying age cut-offs as group assignment might provide results that are more accurate. Yet, given our sample size $(n=125)$ and age distribution, such a MANOVA would have yielded too few group members for valid comparisons particularly in the oldest group(s). In contrast to the MANOVAs, regression analyses suggest that age has robust predictive power for AV usage intention. With every additional year of age, people intend to use AVs less, even when considering their acceptance, perceived safety, and trust in AVs. Significant predictor abilities of gender were consumed as predicted by adding acceptance as another independent variable. Thus, we found evidence that age plays a role in predicting AV usage intention, but that it does not correlate with other attitudes like acceptance or trust. Gender differences in our four attitudes are likely, given the MANOVA p-values, but need further replication to be definitive. Attitude measures, however, trump the predictive power of gender for explaining usage intention.

We were unable to support our research model (Figure 2) rejecting our third hypothesis. Instead, we identified acceptance as the strongest predictor for intention to use whose predictive power was only partially reduced by adding other attitudes to the equation. This finding though seemingly unsurprising demonstrates the importance of clear conceptualisation. When researchers equate acceptance with usage (intentions) (Adell, 2009), they lose (or rename) a strong predictor. With our correlation and regression analyses, we have shown that coordinated definitions and measurements lead to further understandings of people's assessment of emerging technologies. We urge researchers to follow this path and help untangle what has been an ambivalent body of research on $\mathrm{AV}$ attitudes. We also recommend 
researchers to be more rigorous and transparent in their approach by explicitly stating definitions of constructs and by granting full access to all of their methodical materials. This is the only way to make results more comparable and create a reliable body of research on AV attitudes.

\subsection{Limitations}

Our sample represents a disproportionately young, tech-interested, and rather urban population. Thus, positive assessments across scales are unsurprising. However, a population with these characteristics might not vary so much in key attitudes and emotions towards emerging technologies leading us to underestimate findings such as correlations. These underestimations stand in contrast to possible overestimations of effect sizes because "[v]iolations of data level assumptions mean that actual standard error will be greater than the computed standard error" (Garson, 2012). Thus, we have to await replications with larger sample sizes in further research to estimate effect sizes with more confidence. Nonetheless, results from our power analysis show that we can infer with high confidence any correlations $|r| \geq .25$ and regressions $f^{2} \geq .11$. Thus, our study provides a reference point for further research.

Secondly, AVs are still in their experimental phase, driving only accompanied on especially prepared routes with small speed. These conditions make the experience of emotions like fear unlikely and confine attitude research in narrow boundaries. Particularly, the operator compromises the expected level 4 automation and influences user experiences. Even though we collected data in the currently most advanced use cases with higher validity than hypothetical scenarios and simulation studies, we do consider "truly" automated driving to be a topic of the future. Results that are more valid can only be obtained once people can experience AVs regularly and in different scenarios without supervision. For higher internal validity, we refer to simulation studies offering a controlled setting and better oversight.

\section{Acknowledgements}

The authors thank the four student assistants Bent Fuhlrott, Lina Kluy, Lisa Paduch, and Janek Wilhelm (alphabetical order) for their contributions to this research project.

This work was supported by the German Federal Ministry for the Environment, Nature Conservation and Nuclear Safety (Bundesministerium für Umwelt, Naturschutz und nukleare Sicherheit) under Grant 16EM3157-2. The funders had no role in study design, in the collection, analysis and interpretation of data, in the writing of the report, and in the decision to submit the article for publication.

Declaration of interest: none. 


\section{References}

Adell, E. (2009). Driver experience and acceptance of driver support systems - A case of speed adaptation. (Doctoral dissertation), Lund University, Lund. Retrieved from http://lup.lub.lu.se/record/1504012

Adell, E., Várhelyi, A., \& Nilsson, L. (2014). The definition of acceptance and acceptability. In M. A. Regan, T. Horberry, \& A. Stevens (Eds.), Driver acceptance of new technology (pp. 31-42). Surrey, UK: Ashgate Publishing Limited.

Allen, P. J., \& Bennett, K. (2007). SPSS for the health and behavioural sciences. South Melbourne: Thomson Learning.

Bansal, P., \& Kockelman, K. M. (2016). Are we ready to embrace connected and self-driving vehicles? A case study of Texans. Transportation, 45(2), 1-35. doi:10.1007/s11116016-9745-z

Bansal, P., \& Kockelman, K. M. (2017). Forecasting Americans' long-term adoption of connected and autonomous vehicle technologies. Transportation Research: Part A, 95, 49-63. doi:10.1016/j.tra.2016.10.013

Bansal, P., Kockelman, K. M., \& Singh, A. (2016). Assessing public opinions of and interest in new vehicle technologies: An Austin perspective. Transportation Research: Part C, 67, 1-14. doi:10.1016/j.trc.2016.01.019

Charité - Universitätsmedizin Berlin. (2017). Without title. [Map/figure]. Retrieved from https://www.wir-fahren-zukunft.de/en/the-routes/

Charité - Universitätsmedizin Berlin. (2018). Without title. [Photograph]. Retrieved from https://www.wir-fahren-zukunft.de/bilder/\#iLightbox[gallery image 1]/34 
Cho, Y., Park, J., Park, S., \& Jung, E. S. (2017). Technology acceptance modeling based on user experience for autonomous vehicles. Journal of the Ergonomics Society of Korea, 36(2), 87-108. doi:10.5143/JESK.2017.36.2.87

Choi, J. K., \& Ji, Y. G. (2015). Investigating the importance of trust on adopting an autonomous vehicle. International Journal of Human-Computer Interaction, 31(10), 692-702. doi:10.1080/10447318.2015.1070549

Faul, F., Erdfelder, E., Buchner, A., \& Lang, A.-G. (2009). Statistical power analyses using G* Power 3.1: Tests for correlation and regression analyses. Behavior Research Methods, 41(4), 1149-1160. doi:10.3758/BRM.41.4.1149

Fishbein, M., \& Ajzen, I. (1975). Belief, attitude, intention, and behavior: An introduction to theory and research. Reading, MA: Addison-Wesley.

Fraedrich, E., \& Lenz, B. (2016). Societal and individual acceptance of autonomous driving. In M. Maurer, J. C. Gerdes, B. Lenz, \& H. Winner (Eds.), Autonomous driving. Technical, legal and social aspects (pp. 621-640). Berlin \& Heidelberg: Springer.

Garson, G. D. (2012). Testing statistical assumptions. Asheboro, NC: Statistical Associates Publishing.

Haboucha, C. J., Ishaq, R., \& Shiftan, Y. (2017). User preferences regarding autonomous vehicles. Transportation Research: Part C, 78, 37-49. doi:10.1016/j.trc.2017.01.010

Hohenberger, C., Spörrle, M., \& Welpe, I. M. (2016). How and why do men and women differ in their willingness to use automated cars? The influence of emotions across different age groups. Transportation Research: Part A, 94(C), 374-385. doi:10.1016/j.tra.2016.09.022

Hohenberger, C., Spörrle, M., \& Welpe, I. M. (2017). Not fearless, but self-enhanced: The effects of anxiety on the willingness to use autonomous cars depend on individual 
levels of self-enhancement. Technological Forecasting and Social Change, 116, 4052. doi:10.1016/j.techfore.2016.11.011

Huberty, C. J., \& Petoskey, M. D. (2000). Multivariate analysis of variance and covariance. In H. E. A. Tinsley \& S. D. Brown (Eds.), Handbook of applied multivariate statistics and mathematical modeling. New York: Academic Press.

IBM Corp. (2017). IBM SPSS Statistics for Windows (Version 25.0). Armonk, NY: IBM Corp.

Izard, C. E. (1977). Human emotions. New York: Springer Science+Business Media.

Krueger, R., Rashidi, T. H., \& Rose, J. M. (2016). Preferences for shared autonomous vehicles. Transportation Research: Part C, 69, 343-355. doi:10.1016/j.trc.2016.06.015

Kyriakidis, M., Happee, R., \& de Winter, J. C. F. (2015). Public opinion on automated driving: Results of an international questionnaire among 5000 respondents. Transportation Research: Part F, 32, 127-140. doi:10.1016/j.trf.2015.04.014

Madigan, R., Louw, T., Wilbrink, M., Schieben, A., \& Merat, N. (2017). What influences the decision to use automated public transport? Using UTAUT to understand public acceptance of automated road transport systems. Transportation Research: Part F, 50, 55-64. doi:10.1016/j.trf.2017.07.007

Merten, J., \& Krause, R. (1993). DAS (Differentielle Affekt Skala): Arbeiten der Fachrichtung Psychologie, Universität des Saarlandes, Nr. 173. In: Saarbrücken.

Najm, W. G., Stearns, M. D., Howarth, H., Koopmann, J., \& Hitz, J. (2006). Evaluation of an automotive rear-end collision avoidance system. Springfield, VA: U.S. Department of Transportation Research and National Highway Traffic Safety Administration. Retrieved from https://rosap.ntl.bts.gov/view/dot/4307

NHTSA. (2017). Automated driving systems 2.0: A vision for safety. National Highway Traffic Safety Administration \& US Department of Transportation. Retrieved from 


\section{https://www.nhtsa.gov/sites/nhtsa.dot.gov/files/documents/13069a-}

\section{ads2.0 090617 v9a tag.pdf}

Nordhoff, S., de Winter, J., Kyriakidis, M., van Arem, B., \& Happee, R. (2018). Acceptance of driverless vehicles: Results from a large cross-national questionnaire study. Journal of Advanced Transportation, 2018(Article ID 5382192), 22 Pages. doi:10.1155/2018/5382192

Nordhoff, S., de Winter, J., Madigan, R., Merat, N., van Arem, B., \& Happee, R. (2018). User acceptance of automated shuttles in Berlin-Schöneberg: A questionnaire study. Transportation Research: Part F, 58, 843-854. doi:10.1016/j.trf.2018.06.024

Nordhoff, S., van Arem, B., \& Happee, R. (2016). Conceptual model to explain, predict, and improve user acceptance of driverless podlike vehicles. Transportation Research Record: Journal of the Transportation Research Board, 2602, 60-67. doi:10.3141/260208

Norman, G. (2010). Likert scales, levels of measurement and the "laws" of statistics. Advances in Health Sciences Education, 15(5), 625-632. doi:10.1007/s10459-010-9222-y

Osswald, S., Wurhofer, D., Trösterer, S., Beck, E., \& Tscheligi, M. (2012). Predicting information technology usage in the car: Towards a car technology acceptance model. In Proceedings of the 4th International Conference on Automotive User Interfaces and Interactive Vehicular Applications (pp. 51-58): ACM.

Pavlou, P. A. (2003). Consumer acceptance of electronic commerce: Integrating trust and risk with the technology acceptance model. International Journal of Electronic Commerce, 7(3), 101-134. doi:10.1080/10864415.2003.11044275

Payre, W., Cestac, J., \& Delhomme, P. (2014). Intention to use a fully automated car: Attitudes and a priori acceptability. Transportation Research: Part F, 27, 252-263. doi:10.1016/j.trf.2014.04.009 
Rahman, M. M., Lesch, M. F., Horrey, W. J., \& Strawderman, L. (2017). Assessing the utility of TAM, TPB, and UTAUT for advanced driver assistance systems. Accident Analysis \& Prevention, 108, 361-373. doi:10.1016/j.aap.2017.09.011

Regan, M., Cunningham, M., Dixit, V., Horberry, T., Bender, A., Weeratunga, K., . . Hassan, A. (2017). Preliminary findings from the first Australian national survey of public opinion about automated and driverless vehicles. Adelaide: Australia and New Zealand Driverless Vehicle Initiative. Retrieved from https://trid.trb.org/view/1480582

Renaud, D., \& Unz, D. (2006). Die M-DAS - eine modifizierte Version der Differentiellen Affekt Skala zur Erfassung von Emotionen bei der Mediennutzung. Zeitschrift für Medienpsychologie, 18(2), 70-75. doi:10.1026/1617-6383.18.2.70

Rödel, C., Stadler, S., Meschtscherjakov, A., \& Tscheligi, M. (2014). Towards autonomous cars: The effect of autonomy levels on acceptance and user experience. In Proceedings of the 6th International Conference on Automotive User Interfaces and Interactive Vehicular Applications (pp. 1-8): ACM.

Schaefer, K. E., Chen, J. Y., Szalma, J. L., \& Hancock, P. A. (2016). A meta-analysis of factors influencing the development of trust in automation: Implications for understanding autonomy in future systems Human Factors, 58(3), 377-400. doi:10.1177/0018720816634228

Scherer, K. R. (2005). What are emotions? And how can they be measured? Social Science Information, 44(4), 695-729. doi:10.1177/0539018405058216

Scherer, K. R., Shuman, V., Fontaine, J. J. R., \& Soriano, C. (2013). The GRID meets the Wheel: Assessing emotional feeling via self-report. In J. J. R. Fontaine, K. R. Scherer, \& C. Soriano (Eds.), Components of emotional meaning: A sourcebook. Oxford: Oxford University Press. 
Schieben, A., Griesche, S., Hesse, T., Fricke, N., \& Baumann, M. (2014). Evaluation of three different interaction designs for an automatic steering intervention. Transportation Research: Part F, 27, 238-251.

Spyropoulou, I. K., Karlaftis, M. G., \& Reed, N. (2014). Intelligent speed adaptation and driving speed: Effects of different system HMI functionalities. Transportation Research: Part F, 24, 39-49.

Van der Laan, J. D., Heino, A., \& de Waard, D. (1997). A simple procedure for the assessment of acceptance of advanced transport telematics. Transportation Research: Part C, 5(1), 1-10. doi:10.1016/S0968-090X(96)00025-3

Verberne, F. M. F., Ham, J., \& Midden, C. J. H. (2015). Trusting a virtual driver that looks, acts, and thinks like you. Human Factors, 57(5), 895-909. doi:10.1177/0018720815580749

Zoellick, J. C., Kuhlmey, A., Schenk, L., Schindel, D., \& Blüher, S. (2019). Assessing acceptance of electric automated vehicles after exposure in a realistic traffic environment. PLoS One, 14(5), e0215969. doi:10.1371/journal.pone.0215969 


\section{CHIARITÉ}

\section{Questionnaire about driverless busses at the Charité}

Thank you very much for participating in this survey!

Please tick the box next to the statement you find most appropriate or make the respective note. Your data will be processed anonymously. Please consult the contact person if you have any questions.

\begin{tabular}{|l|c|c|c|}
\hline How old are you? & Age: & \multicolumn{2}{|c|}{ Years } \\
\hline Please indicate your gender. & $\square$ female & $\square$ male & $\square$ prefer not to say \\
\hline Do you have a driver's license for passenger cars? & $\square$ Yes & $\square$ No \\
\hline
\end{tabular}

How did you feel on the ride with the electric automated bus? Please give your evaluation for the following terms.

\begin{tabular}{|l|c|c|c|c|c|}
\hline & Very weak & Weak & Neutral & Strong & Very strong \\
\hline Bored & $\square$ & $\square$ & $\square$ & $\square$ \\
\hline Silly & $\square$ & $\square$ & $\square$ & $\square$ & $\square$ \\
\hline Bored stiff & $\square$ & $\square$ & $\square$ & $\square$ & $\square$ \\
\hline Surprised & $\square$ & $\square$ & $\square$ & $\square$ & $\square$ \\
\hline Uninvolved & $\square$ & $\square$ & $\square$ & $\square$ & $\square$ \\
\hline Scared & $\square$ & $\square$ & $\square$ & $\square$ & $\square$ \\
\hline Amused & $\square$ & $\square$ & $\square$ & $\square$ & $\square$ \\
\hline Fearful & $\square$ & $\square$ & $\square$ & $\square$ & $\square$ \\
\hline Amazed & $\square$ & $\square$ & $\square$ & $\square$ & $\square$ \\
\hline Astonished & $\square$ & $\square$ & $\square$ & $\square$ & $\square$ \\
\hline Fun-loving & $\square$ & $\square$ & $\square$ & $\square$ & $\square$ \\
\hline Afraid & $\square$ & $\square$ & $\square$ & $\square$ & $\square$ \\
\hline
\end{tabular}

How safe did you feel on the ride with the electric automated bus?

Very unsafe

Unsafe

Neutral

Safe

Very safe 
In the following, we are interested in your opinion about automated vehicles in local public transport.

\begin{tabular}{|l|c|c|c|c|c|}
\hline & Disagree & $\begin{array}{c}\text { Some- } \\
\text { what } \\
\text { disagree }\end{array}$ & $\begin{array}{c}\text { Un- } \\
\text { decided }\end{array}$ & $\begin{array}{c}\text { Some- } \\
\text { what } \\
\text { agree }\end{array}$ & Agree \\
\hline $\begin{array}{l}\text { Assuming I had access to an autonomous vehicle, I } \\
\text { intend to use it. }\end{array}$ & $\square$ & $\square$ & $\square$ & $\square$ & $\square$ \\
\hline I feel safe when using autonomous vehicles. & $\square$ & $\square$ & $\square$ & $\square$ & $\square$ \\
\hline $\begin{array}{l}\text { I trust autonomous vehicles, because they keep my best } \\
\text { interests in mind. }\end{array}$ & $\square$ & $\square$ & $\square$ & $\square$ \\
\hline $\begin{array}{l}\text { If autonomous vehicles are available, I plan to use one } \\
\text { in the next months. }\end{array}$ & $\square$ & $\square$ & $\square$ & $\square$ & $\square$ \\
\hline Using autonomous vehicles decreases the accident risk. & $\square$ & $\square$ & $\square$ & $\square$ & $\square$ \\
\hline Autonomous vehicles keep promises and commitments. & $\square$ & $\square$ & $\square$ & $\square$ & $\square$ \\
\hline Autonomous vehicles are trustworthy. & $\square$ & $\square$ & $\square$ & $\square$ & $\square$ \\
\hline I believe using autonomous vehicles is dangerous. & $\square$ & $\square$ & $\square$ & $\square$ & $\square$ \\
\hline $\begin{array}{l}\text { Given I had access to an autonomous vehicle, I predict } \\
\text { that I would use it. }\end{array}$ & $\square$ & $\square$ & $\square$ & $\square$ & $\square$ \\
\hline Using autonomous vehicles requires increased attention. & $\square$ & $\square$ & $\square$ & $\square$ & $\square$ \\
\hline
\end{tabular}

\section{My judgements of automated vehicles are:}

\begin{tabular}{r|c|l} 
useful & $\square \square \square \square \square$ & useless \\
pleasant & $\square \square \square \square \square$ & unpleasant \\
bad & $\square \square \square \square \square$ & good \\
nice & $\square \square \square \square \square$ & annoying \\
effective & $\square \square \square \square \square$ & superfluous \\
irritating & $\square \square \square \square \square$ & likeable \\
assisting & $\square \square \square \square \square$ & worthless \\
undesirable & $\square \square \square \square \square$ & desirable \\
raising alertness & $\square \square \square \square \square$ & sleep-inducing
\end{tabular}

Did we leave something out? Please give us your comments about the project or the vehicles. 


\section{CHIARITÉ}

\section{Fragebogen zu fahrerlosen Bussen an der Charité}

Vielen Dank für Ihre Teilnahme an dieser Umfrage!

Bitte kreuzen Sie die jeweils zutreffende Angabe an bzw. schreiben die Information auf. Ihre Daten werden anonym verarbeitet. Bei Fragen wenden Sie sich bitte an die Ansprechperson.

\begin{tabular}{|c|c|c|c|}
\hline Wie alt sind Sie? & \multicolumn{3}{|c|}{ Alter: __ Jahre } \\
\hline Bitte nennen Sie Ihr Geschlecht. & $\square$ weiblich & $\square$ männlich & $\square$ keine Angabe \\
\hline Haben Sie einen PKW-Führerschein? & \multicolumn{2}{|c|}{$\square \mathrm{Ja}$} & $\square$ Nein \\
\hline
\end{tabular}

Wie haben Sie sich während der Fahrt mit dem elektrischen, automatisierten Kleinbus gefühlt? Bitte geben Sie Ihre Einschätzung zu den folgenden Begriffen.

\begin{tabular}{|l|c|c|c|c|c|}
\hline & $\begin{array}{c}\text { Sehr } \\
\text { schwach }\end{array}$ & Schwach & Teils/teils & Stark & Sehr stark \\
\hline Gelangweilt & $\square$ & $\square$ & $\square$ & $\square$ & $\square$ \\
\hline Vergnügt & $\square$ & $\square$ & $\square$ & $\square$ & $\square$ \\
\hline Angeödet & $\square$ & $\square$ & $\square$ & $\square$ & $\square$ \\
\hline Überrascht & $\square$ & $\square$ & $\square$ & $\square$ & $\square$ \\
\hline Unbeteiligt & $\square$ & $\square$ & $\square$ & $\square$ & $\square$ \\
\hline Erschreckt & $\square$ & $\square$ & $\square$ & $\square$ & $\square$ \\
\hline Amüsiert & $\square$ & $\square$ & $\square$ & $\square$ & $\square$ \\
\hline Furchtsam & $\square$ & $\square$ & $\square$ & $\square$ & $\square$ \\
\hline Erstaunt & $\square$ & $\square$ & $\square$ & $\square$ & $\square$ \\
\hline Verblüfft & $\square$ & $\square$ & $\square$ & $\square$ & $\square$ \\
\hline Erheitert & $\square$ & $\square$ & $\square$ & $\square$ & $\square$ \\
\hline Ängstlich & $\square$ & $\square$ & $\square$ & $\square$ & $\square$ \\
\hline
\end{tabular}

Wie sicher haben Sie sich bei der Fahrt mit dem elektronischen, automatisierten Kleinbus gefühlt? 
Im Folgenden interessiert uns Ihre Meinung zu automatisierten Fahrzeuge im öffentlichen Personennahverkehr.

\begin{tabular}{|c|c|c|c|c|c|}
\hline & $\begin{array}{l}\text { Stimme } \\
\text { nicht zu }\end{array}$ & $\begin{array}{c}\text { Stimme } \\
\text { eher } \\
\text { nicht zu }\end{array}$ & $\begin{array}{l}\text { Teils- } \\
\text { teils }\end{array}$ & $\begin{array}{l}\text { Stimme } \\
\text { eher zu }\end{array}$ & $\begin{array}{l}\text { Stimme } \\
\mathrm{zu}\end{array}$ \\
\hline $\begin{array}{l}\text { Wenn ich Zugang zu einem automatisierten Fahrzeug hätte, } \\
\text { dann würde ich es vermutlich nutzen. }\end{array}$ & $\square$ & $\square$ & $\square$ & $\square$ & $\square$ \\
\hline $\begin{array}{l}\text { Ich würde mich sicher fühlen, wenn ich automatisierte } \\
\text { Fahrzeuge nutze. }\end{array}$ & $\square$ & $\square$ & $\square$ & $\square$ & $\square$ \\
\hline $\begin{array}{l}\text { Ich vertraue automatisierten Fahrzeugen, weil sie meine } \\
\text { Interessen berücksichtigen. }\end{array}$ & $\square$ & $\square$ & $\square$ & $\square$ & $\square$ \\
\hline $\begin{array}{l}\text { Sobald automatisierte Fahrzeuge verfügbar sind, plane ich, } \\
\text { eines in den nächsten Monaten zu nutzen. }\end{array}$ & $\square$ & $\square$ & $\square$ & $\square$ & $\square$ \\
\hline Automatisierte Fahrzeuge zu nutzen, verringert das Unfallrisiko. & $\square$ & $\square$ & $\square$ & $\square$ & $\square$ \\
\hline $\begin{array}{l}\text { Automatisierte Fahrzeuge halten, was sie versprechen und } \\
\text { zusagen. }\end{array}$ & $\square$ & $\square$ & $\square$ & $\square$ & $\square$ \\
\hline Automatisierte Fahrzeuge sind vertrauenswürdig. & $\square$ & $\square$ & $\square$ & $\square$ & $\square$ \\
\hline $\begin{array}{l}\text { Ich glaube, dass das Nutzen von automatisierten Fahrzeugen } \\
\text { gefährlich ist. }\end{array}$ & $\square$ & $\square$ & $\square$ & $\square$ & $\square$ \\
\hline $\begin{array}{l}\text { Wenn ich Zugang zu einem automatisierten Fahrzeug hätte, } \\
\text { dann würde ich es auf jeden Fall nutzen. }\end{array}$ & $\square$ & $\square$ & $\square$ & $\square$ & $\square$ \\
\hline $\begin{array}{l}\text { Automatisierte Fahrzeuge zu nutzen, erfordert erhöhte } \\
\text { Aufmerksamkeit. }\end{array}$ & $\square$ & $\square$ & $\square$ & $\square$ & $\square$ \\
\hline
\end{tabular}

\section{Meine Beurteilung für automatisierte Fahrzeuge lautet:}

\begin{tabular}{|r|l|l|}
\hline nützlich & $\square \square \square \square \square$ & nutzlos \\
\hline angenehm & $\square \square \square \square \square$ & unangenehm \\
\hline schlecht & $\square \square \square \square \square$ & gut \\
\hline erleichternd & $\square \square \square \square \square$ & lästig \\
\hline effektiv & $\square \square \square \square \square$ & überflüssig \\
\hline ärgerlich & $\square \square \square \square \square$ & erfreulich \\
\hline hilfreich & $\square \square \square \square \square$ & wertlos \\
\hline nicht wünschenswert & $\square \square \square \square \square$ & wünschenswert \\
\hline anregend & $\square \square \square \square \square$ & einschläfernd \\
\hline
\end{tabular}

Haben wir etwas nicht beachtet? Bitte geben Sie uns Ihre Anmerkungen zum Projekt oder den Fahrzeugen. 